\title{
An Economic Production Model with Flexibility
}

\author{
Ajay Kumar Agrawal ${ }^{1}$, Alok Kumar ${ }^{2}$ \\ ${ }^{1}$ Department of Mathematics, Motilal Nehru College, University of Delhi, India \\ ${ }^{2}$ Department of Mathematics, Deshbandhu College, University of Delhi, India alok.kadiyan@gmail.com
}

\begin{abstract}
This paper develops a model to determine the optimal reliability and production rate that achieves the biggest total integrated profit for an imperfect production process under allowable shortage. In this system, production facility may shift 'in-control' state to an 'out-control state' at any random time. The basic assumption of the classical EPL model is that 100\% of product is of perfect quality. But practically this is not true. More specifically, the paper extends the paper of Sana (S.S.Sana, 2010, an economic production lot size model in an imperfect production system. European Journal of Operational Research 201, 158-170). Here we consider two type of production process in a cycle time. One is 'in-control' state at the starting of the production which provides conforming quality items and second one is 'out-control' state after certain time due to higher production rate and production run time. The proposed model is formulated assuming that a certain percent of total product which described by a function is defective. The imperfect quality items are reworked at a cost to restore its quality to the original one. The total cost function is illustrated by numerical examples and also its sensitivity analysis is carried out.
\end{abstract}

Keywords: EPQ Model, Imperfect Production process, 'In-control' state, 'Out-control' state,

\section{Introduction}

It is generally admitted that inventory management is affected by the imperfect quality of goods and this aspect has to be taken into account. In the last few decades, the development of inventory control models and their uses are popularized by academicians as well as industries. However, one of the weaknesses of current inventory models is the unrealistic assumption that all items produced are of good quality. In classical economic production lot size (EPL) model, the production rate of a machine is assumed to be predetermined and inflexible (Hax and Candea , 1984). However, production rate can be easily changed (Schweitzer and Seidmaan, 1991). In other words, production rate in many cases should be treated as decision variable. Empirical observations indicate that as machine production rate is increased, tool or die costs increase (Drozda and Wick, 1987). The treatment of production rate as a decision variable is especially appropriate for automated technologies that are volume flexibility. Volume flexibility of a manufacturing system is defined as its ability to be operated profitably at different overall output levels. Volume flexibility permits a manufacturing system to adjust production upwards or downwards within wide limit period to the start of production of a lot. It is a major component of Flexible Manufacturing System (FMS). It helps to reduce the rate of production to avoid rapid accumulation of inventories and non-conforming (defective) items. Advances in computer sciences have contributed to development of Volume Flexible Manufacturing Systems. In modern automobile industries, computer-controlled machines have been introduced to increase productivity and high quality of products. The speed of production at such machines is controlled by a computer. It is rationale that an increasing rate of production increases the probability of components (machinery parts, labor etc.) failure and thus nonconforming quality items increases. Generally, percentage of defective items increases with increase of production rate and production-run time. Because, almost all machinery system may undergo malfunctioning or unsatisfactory performance after some time and also these increase with time. At the start of production, process is 'in-control' state and the items produced are of conforming quality. After some time, it may shift to an 'out-of-control' state while in process, there by resulting in the production of nonconforming quality items.

Several researchers have initiated to analyze various problems related to imperfect production process by devoting their time and efforts. According to Rosenblatt and Lee (1986), the time of shift from 'in-control' state to 'outof-control' state follows an exponential distribution with a mean $1 / \mathrm{m}$, assuming $\mathrm{m}$ is a small value. They have derived an Economic Manufacture Quantity (EMQ) formula by using approximate value up to second order of Maclaurin series expansion of the exponential function. Lee and Rosenblatt (1987, 1989), on the basis of RL model (Rosenblatt and Lee, 1986), have determined an optimal production run-time and optimal inspection policy simultaneously to monitor the production process. Cheng (1991) have derived a closed form expression for the optimal demand to satisfy order quantity and process reliability while the demand exceeds supply and the production process is imperfect. Khouja and Mehrez (1994) have considered the elapsed time until the production process shifts to an 'out-of-control' state to be an exponentially distributed random variable. The results of this model indicate the aspect for both weak and strong relationship between the rate of production and process quality. Hariga and Ben-Daya(1998) and Kim and Hong (1999) have extended RL model, considering the general time required to shift distribution and an optimal productionrun-time shown to be unique. Makis (1998) has studied several properties of the optimal production and inspection policies in imperfect production process. Some of the above modeler has showed that defective items can be reworked instantaneously at a cost. In the model of Wang (2004), an imperfect EMQ model for production which are repaired and sold under a free-repair warranty policy (i.e., the cost incurred by a defective item after its sale) discussed by Yeh et al. (2000) has been extended to consider general shift distribution. Sheu and Chen (2004) have developed a lot- 


\section{International Journal of Science and Research (IJSR) ISSN (Online): 2319-7064}

Index Copernicus Value (2013): 6.14 | Impact Factor (2014): 5.611

sizing model to determine the level of preventive maintenance for an imperfect process control. Lee (2005a-c) has extended the model to increase the service level and reduce the defectives in imperfect production system with imperfect quality of the products and imperfect supplied quantity. Chen and Lo (2006) have developed an imperfect production system with allowable shortage and the products are sold with free minimal repair warranty. The probabilities of non-conforming items in both the states (out-of-control and in-control) are different. They have formulated a cost minimization model in which the production-run-length and the time length when back-order is replenished are decision variables. Lee (2006) has presented the investment model with respect to repetitive inspections and measurement equipment in imperfect production process. Sana et al. (2007a) have extended an EPLS (Economic Production Lot size) model which accounts for production system producing items of perfect as well as imperfect quality. The probability of imperfect quality items increases with increase of production-run-time because of machinery problems, impatience of labor staff and improper distribution of raw materials. They have assumed that the demand rate of perfect quality items is constant whereas the demand rate of defective items which are not repaired is a function of reduction rate. In another model, Sana et al. (2007b) have developed a volume flexible inventory model with an imperfect production system where demand rate of conforming quality items is a random variable and the demand rate of defective items is a function of a random variable and reduction rate. Giri and Dohi (2007) have studied a problem inspection scheduling in an imperfect production process in which the manufacturing process may shift from 'in-control' state to an 'out-of-control' state. The shift time follows an arbitrary probability distribution with increasing hazard (failure) rate and the products are sold with a free minimal repair warranty. The inspection process monitors the production process which in turn reduces the number of imperfect quality products. Liao (2007) has investigated an imperfect production process that requires production corrections and imperfect maintenance. Two states of production process are occur, namely state I (outof-control state) and state II (in-control state). In 'out-ofcontrol' state, the product is not perfect and a part is rejected (reworking is impossible) with a probability 'q'. The product is perfect (good quality) with a probability '(1-q)'. The mean loss cost due to reproduction through production correction per total expected cost until the $\mathrm{N}+1$ 'out-of-control' states are entered successively is determined. Lo et al. (2007) have extended a production-inventory model in aspect of both the manufacturer and the retailer. They have assumed a varying rate of deterioration, partial back-ordering, inflation, imperfect production process and multiple deliveries. The elapsed time for the production process shift to imperfect production is assumed to be exponential distribution (same as Khouja and Mehrez, 1994). Panda et al. (2008) have modeled an Economic Production Lot size model for imperfect items in which production rate is considered as fixed quantity and the demand rate is probabilistic under certain budget and shortage constraints. They also have assumed that the percentage of defective items is stochastic and the natures of uncertainty in the constraints are stochastic or fuzzy. In this case, the percentage of defective item is independent of production rate and production-run- time. Lee (2008) has developed a maintenance model in multi-level multi-stage system. According to his model, the investment in preventive maintenance is to reduce the variance and the deviation of the mean from the target value of the quality characteristics that reduce the proportion of defectives also to increase reliability of the product. The proportion of defectives can be linked to the cost of manufacturing, cost of inventory, and loss of profit. The total costs in this model include the cost of manufacturing, setup cost, holding cost, loss of profit and warranty cost.

In most EOQ (Economic Order Quantity) model, the assumption is that $100 \%$ of produced units are of good (perfect) quality. This unrealistic assumption may not be valid for any production environment. Schwaller (1988) has presented a procedure that extends EOQ models by adding the assumptions that defectives of a known proportion are present in incoming lots and that fixed and variable inspection costs are incurred in finding and removing the items. Zhang and Gerchak (1990) have considered a joint lot sizing and inspection policy studied under an EOQ model where a random proportion of units are defective. These defectives cannot be used and thus must be replaced by nondefective ones. Khouja and Mehrez (1994) have developed an EPLS with imperfect quality. They have taken the percentage of defective items as a product of production rate and production run time. Salameh and Jaber (2000) have developed an economic production/inventory quantity model for items with imperfect quality. They have assumed that poor quality items are sold as a single batch at the end of $100 \%$ screening process. Hayek and Salameh (2001) have developed an EPQ (Economic Production Quantity) model considering a percent of total products as defective items that has a uniform distribution. The basic assumptions of this model are: backorders are permitted, all defective items are reworked and become perfect quality and rework time is also considered. Goyal and Cardenas-Barron (2002) have reworked on the paper of Salameh and Jaber (2000) and presented practical approach to find out the optimal lot size. Chiu (2003) has extended Hayek and Salameh's (2001) model by assuming a portion of the defective items are reworked to make them good quality item instead of reworking on all of the defective items and the remaining items are sold at a price. Chan et al. (2003) have extended an EPQ model using similar assumptions as Salameh and Jaber (2000). They have classified products as good quality, good quality after reworking, imperfect quality and scrap. Crucial assumptions of these models are not allowing backorders, reworking time is zero and imperfect quality products are sold at a price. Chang (2004) has developed an EOQ model with fuzzy defective rate and demand. Papachristos and Konstantaras (2006) have considered the issue of nonshortage in inventory models with imperfect quality where the rate of defective is a random variable. Referring to the models of Salameh and Jaber (2000) and Chan et al. (2003), they have pointed out that the conditions proposed as sufficient ones to guarantee that shortages will not occur, cannot ensure it. Maddah and Jaber (2008) have identified a flaw in the work of Salameh and Jaber (2000) on the EOQ model with a random fraction of imperfect quality items subject to $100 \%$ screening, and proposed a new model that rectified this flaw using renewal theory. This model leads to 


\section{International Journal of Science and Research (IJSR) \\ ISSN (Online): 2319-7064}

Index Copernicus Value (2013): 6.14 | Impact Factor (2014): 5.611

simple expressions for the expected profit per unit time and the optimal order quantity.

Khouja and Mehrez (1994), Chung and Hou (2003) and some other researchers have used a function for percentage of defective items as a product of production rate and production run time. Sana (2010) has assumed the percentage of defective items varies non-linearly with production rate and production-run-time.

All of the above-mentioned models assume that shortages are not permitted to occur. Nevertheless, in many practical situations, stock out is unavoidable due to various uncertainties. Therefore, the occurrence of shortage in inventory is a natural phenomenon. The main purpose of this paper is to generalize Sana (2010) to assume the shortage is allowed. In addition in this paper we consider unit production cost dependent selling price as it is very much important for many realistic practical situations. Also in this study we consider screening cost of the item during production process as it should not be neglected.

It starts with shortage. After a certain time, the production starts with a variable production rate up to an optimal time. During production-run-time, the manufacturing process may shift to an 'out-of-control' state after certain time that follows exponential distribution function. In 'out-of-control' state, a percent of produced items are defective. The defective items are reworked immediately at a cost. Then, I have formulated a profit function, and maximized it by considering the production lot size and production rate as decision variables.

The paper is organized as follows: Section 2 presents fundamental assumptions and notation. Section 3 formulates the model. Section 4 provides numerical examples. Sensitivity analysis is discussed in Section 5. Section 6 concludes the paper.

\section{Fundamental Assumptions and Notations}

The following assumptions and notations are considered to develop the model:

\section{Assumptions}

1) At the starts of each production cycle, the production process is always in an in-control state and perfect items are produced.

2) The production process shifts from the in-control state to an out-control state. During out-control state imperfect quality items are produced and these are reworked at a cost immediately
3) An elapsed time until shift is arbitrarily distributed with mean and variance.

4) the rate of production and lot size are decision variables

5) lead time is zero

6) shortage is completely backordered

7) the model is developed for a single item

8) time horizon is infinite

\section{Notations:}

P- Production rate in units per year

Q- Production lot size in unit

$\mathrm{T}$ - Cycle time in years

$t_{2}+t_{3}$ - Production runs time in year

$t_{1}$ - Shortage period

$C_{s}$ - Setup cost

$\mathrm{W}$ - Selling price per unit time is determined by a mark up over the unit production cost i.e. $\mathrm{W}=\mu \mathrm{C}(\mathrm{P})$

$C_{h}$ - Holding cost per unit per unit time

R- Cost to reworked one unit

D- Annual demand

B- The maximum backordering quantity in units

b- The backordering cost per unit

d- The screening cost per unit

$\mathrm{C}(\mathrm{P})$ - Unit production cost as a function of the production rate

$\tau$ - An exponential random variable that depends on $\mathrm{P}$ and denotes the elapsed time until the process shifts to the outcontrol state

$1 / f(P)-$ Mean of $\tau$. Here $f(P)$ is an increasing function of $P$ $\lambda(t, \tau, P)$ - Percentage of the defective items produced at time $t$ when the machine is in the out- control state

$\mathrm{N}$ - Number of defective items in a production cycle

$\mathrm{E} \pi$ - Integrated expected profit per unit time

\section{Formulation of Model}

The system operates as follow. It starts at $t=0$ at a demand rate $\mathrm{D}$ up to time $\mathrm{t}=t_{1}$ to allow shortage of $\mathrm{B}$ units to occur. Then production starts where the inventory level increases at a rate $\mathrm{P}-\mathrm{D}$ in order to satisfy the demand and to eliminate the entire shortages of $B$ units, where the inventory level become zero by time $t_{1}+t_{2}$. At this time, the inventory level starts to go up with a rate P-D until time $t_{1}+t_{2}+t_{3}$. At time $\mathrm{t}=t_{3}$ the stock of inventory is (P-D) $t_{3}$. During time span $\left[0, t_{4}\right]$ this stock level depletes satisfying the demand in the demand in the market and it reaches at zero level at time $t_{4}$. 


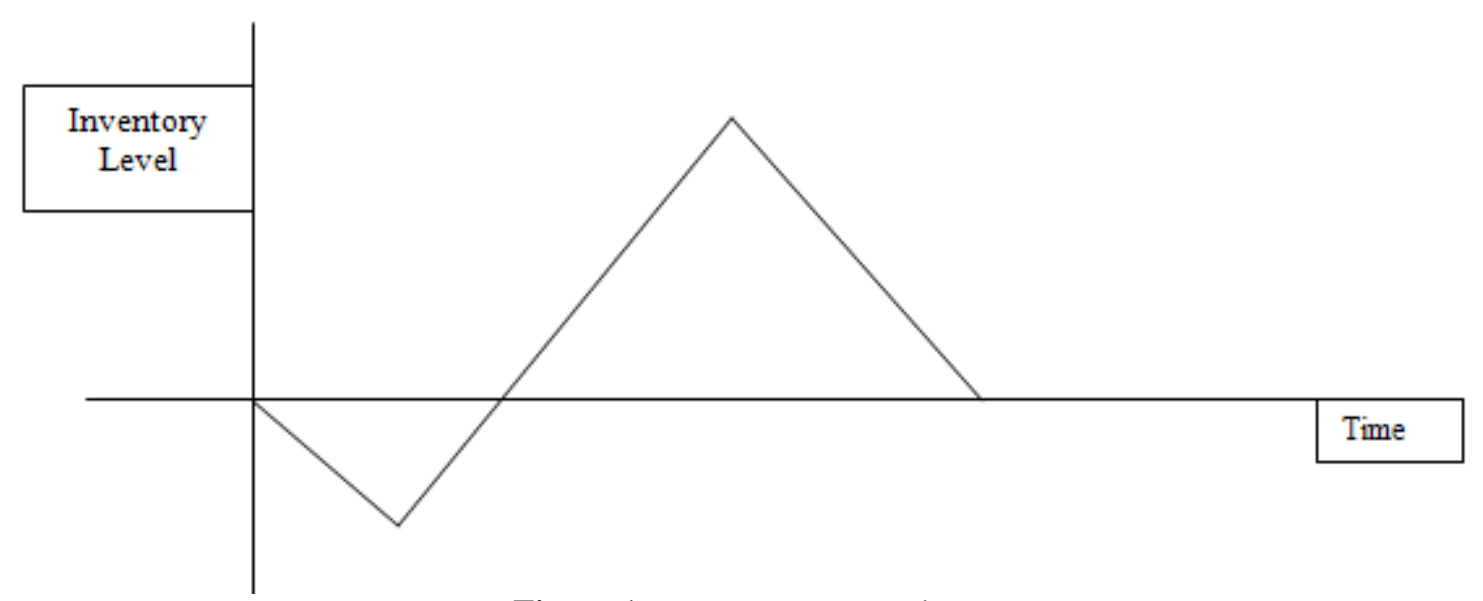

Figure 1: Inventory versus Time

Here total lot size is Q. so the production is $t_{2}+t_{3}=\mathrm{Q} / \mathrm{P}$. in the mode, production process is so adjusted that the produced items at the beginning of the production are of conforming quality up to a certain time $\tau\left(>t_{1}+t_{2}\right)$ (i.e. in control state). After which the production process shifts to an out-control state. In out-control state; some of the produced items are of non-conforming quality. The production rate of defective items is $\lambda(t, \tau, P)$ percent of production rate $\mathrm{P}$. here $\lambda(\mathrm{t}, \tau, \mathrm{P})$ is defined as

$\lambda(\mathrm{t}, \tau, \mathrm{P})=\alpha \mathrm{P}^{\beta}(t-\tau)^{\theta}$ where $0<\alpha<1,0 \leq \beta \leq 1,0 \leq \theta<1$ and $\mathrm{t} \geq \tau$

In general, the percentage of defective items increases with increase of production rate and production run time. The formulation of the function shows that it is an increasing function of production rate and production run time simultaneously. These total defective items during $[0, \tau]$ is 0 and $\left[\tau, t_{3}\right]$ is

$\mathrm{N}=P \int_{\tau}^{t_{3}} \alpha P^{\beta}(t-\tau)^{\theta} d t=\frac{\alpha P^{\beta+1}}{\theta+1}\left(t_{3}-\tau\right)^{\theta+1}$
$\mathrm{N}=\left\{\begin{array}{l}0 \text { if } \tau \geq t_{3} \\ \frac{\alpha P^{\beta+1}}{\theta+1}\left(t_{3}-\tau\right)^{\theta+1} \text { if } \tau \leq t_{3}\end{array}\right.$

The distribution function of out-control state is $G(\tau)=$ $1-e^{-f(P) \tau}$ such that

$$
\int_{0}^{\infty} d G(\tau)=f(P) \int_{0}^{\infty} e^{-f(P) \tau} d \tau=1
$$

The exponential distribution has often been used to describe the elapsed time to failure if many components of the machinery system. The mean time to failure is decreasing function of P. therefore, the expected number of defective items in a production lot size $\mathrm{Q}$ is

$$
\begin{aligned}
& \mathrm{E}(\mathrm{N})=\frac{\alpha P^{\beta+1}}{\theta+1} \int_{0}^{t_{3}}\left(t_{3}-\tau\right)^{\theta+1} d G(\tau)= \\
& \frac{\alpha P^{\beta+1}}{\theta+1} \int_{0}^{t_{3}}\left(t_{3}-\tau\right)^{\theta+1} f(P) e^{-f(P) \tau} d \tau
\end{aligned}
$$

Therefore, the total defective items in the cycle is

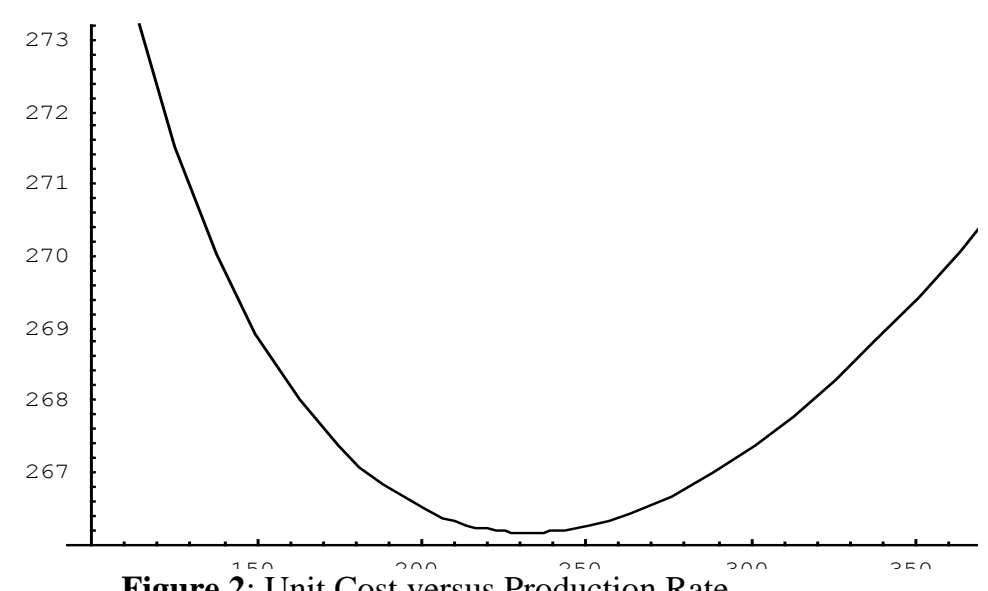

Figure 2: Unit Cost versus Production Rate

The unit production cost is

$\mathrm{C}(\mathrm{P})=r_{m}+A+\frac{g}{P^{\gamma}}+\eta P^{\delta}$
This disproportional combination between fixed and variable factors may enhance the cost of production. That is why the cost function is U-shaped (see fig.-2) 
The minimum cost

$$
\begin{gathered}
C_{\min }=r_{m}+A+g\left(\frac{\eta \delta}{g \gamma}\right)^{\frac{\gamma}{\gamma+\delta}}+\eta\left(\frac{\eta \delta}{g \gamma}\right)^{-\frac{\gamma}{\gamma+\delta}} \text { occurs } \\
\text { at } P_{\min }=\left(\frac{g \gamma}{\eta \delta}\right)^{\frac{1}{\gamma+\delta}}
\end{gathered}
$$

The shortage cost during time $t_{1}=\frac{b B t_{1}}{2}=\frac{b B^{2}}{2 D}$ $\left[\because D t_{1}=B\right.$, i.e. $\left.t_{1}=\frac{B}{D}\right]$

Now $P t_{2}=D t_{1}+D t_{2}=B+D t_{2} \Leftrightarrow t_{2}=\frac{B}{P-D}$

Thus the shortage cost during the time $t_{2}=\frac{1}{2} b B t_{2}=$ $\frac{b B^{2}}{2(P-D)}$

Hence, Shortage cost during time $t_{1}+t_{2}=\frac{b B^{2} P}{2 D(P-D)}$ Now since $\left(t_{2}+t_{3}\right) P=Q \Leftrightarrow t_{3}=\frac{Q(P-D)-B P}{P(P-D)}$

$$
\begin{array}{r}
\mathrm{E} \pi(\mathrm{Q}, \mathrm{P})=\frac{D}{Q}\left[Q W-Q C(P)-d Q-C_{s}-\frac{C_{h}[Q(P-D)-B P]^{2}}{2 P D(P-D)}-\frac{b B^{2} P}{2 D(P-D)}-R E(N)\right] \\
=D W-D C(P)-d D-\frac{D}{Q} C_{s}-\frac{C_{h}[Q(P-D)-B P]^{2}}{2 P Q(P-D)}-\frac{b B^{2} P}{2 Q(P-D)}-R\left\{\frac{D \alpha}{Q(\theta+1)}\right\} P^{\beta+1} \int_{0}^{t_{3}}\left(t_{3}-\tau\right)^{\theta+1} f(P) e^{-f(P) \tau} d \tau
\end{array}
$$

\section{Numerical Examples}

Ex. 1 The values of the parameters are considered in appropriate units as follows

$\alpha=0.0005, \gamma=1, \delta=2, \eta=\$ 0.00001, \beta=0, r_{m}=\$ 200, \mathrm{~g}$ $=2500, \mathrm{~A}=\$ 50, \mathrm{D}=200$ units $C_{h}=\$ 10, C_{s}=\$ 1000, \mathrm{R}=$ $\$ 100, f(P)=0.0005 P, d=\$ 0.5 /$ unit, $b=\$ 10 /$ unit, $B=500$, the required optimal solution are $Q^{*}=1238.29$ units, $P^{*}=$ 480.87 units, $C\left(P^{*}\right)=\$ 257.51, \mu=1.5$

$\mathrm{W}=\mu \mathrm{C}\left(P^{*}\right)=\$ 386.26$, Rework Cost $\left(R C^{*}\right)=\$ 0.2929$, Inventory Cost $\left(I C^{*}\right)=\$ 2115.34$, Setup Cost $\left(S C^{*}\right)$ $=\$ 161.55, E \pi^{*}=\$ 23363.1$ and

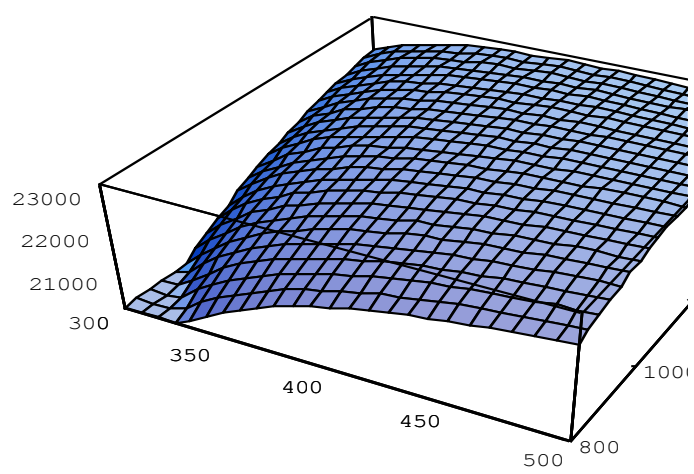

Figure 3: Expected Profit versus production rate and lot size of Example 1

\begin{tabular}{|l|l|l|l|l|}
\hline$t_{1}$ & $t_{2}$ & $t_{3}$ & $t_{4}$ & $\mathrm{~T}$ \\
\hline 2.5 & 1.78 & 0.793 & 1.11 & 6.9 \\
\hline
\end{tabular}




\section{International Journal of Science and Research (IJSR) \\ ISSN (Online): 2319-7064}

Index Copernicus Value (2013): 6.14 | Impact Factor (2014): 5.611

Sensitivity analysis of example 1.

\begin{tabular}{|c|c|c|c|c|c|c|c|}
\hline Parameters changes (in \%) & $P^{*}$ & $Q^{*}$ & $S C^{*}$ & $I C^{*}$ & $R C^{*}$ & $\mathrm{C}\left(P^{*}\right)$ & $E \pi^{*}$ \\
\hline g-50\% & -23.95 & +28.51 & -22.36 & +25.62 & +26.15 & -01.16 & -01.76 \\
\hline$-25 \%$ & -10.41 & +08.80 & -08.07 & +07.42 & +24.71 & -00.38 & -00.53 \\
\hline$+25 \%$ & +08.75 & -05.25 & +05.59 & -04.25 & -04.43 & +00.38 & -00.20 \\
\hline$+50 \%$ & +16.04 & -08.80 & +09.93 & -07.80 & -07.98 & +00.77 & -00.34 \\
\hline$\eta-50 \%$ & +26.04 & -12.52 & +14.28 & -10.63 & -10.99 & -00.77 & -02.20 \\
\hline$-25 \%$ & +10.20 & -05.98 & +06.21 & -04.72 & -04.95 & -00.38 & -02.88 \\
\hline$+25 \%$ & -07.08 & +05.65 & -05.59 & +05.05 & +05.18 & +00.38 & -03.88 \\
\hline$+50 \%$ & -12.50 & +11.22 & -09.93 & +10.49 & +10.61 & +00.38 & -04.28 \\
\hline$\alpha-50 \%$ & $\mathrm{nc}$ & nc & nc & nc & -50.01 & nc & nc \\
\hline$-25 \%$ & $\mathrm{nc}$ & $\mathrm{nc}$ & $\mathrm{nc}$ & nc & -25.02 & $\mathrm{nc}$ & $\mathrm{nc}$ \\
\hline$+25 \%$ & nc & nc & nc & $\mathrm{nc}$ & +24.99 & $\mathrm{nc}$ & $\mathrm{nc}$ \\
\hline$+50 \%$ & nc & nc & nc & nc & +49.98 & nc & -00.004 \\
\hline$C-50 \%$ & +00.83 & +22.69 & -18.63 & +54.23 & +149.88 & nc & +00.30 \\
\hline$h-50 \%$ & +00.41 & +08.07 & -07.45 & +21.18 & +49.02 & nc & -00.40 \\
\hline $\begin{array}{l}-25 \% \\
-250 \%\end{array}$ & -00.20 & -05.25 & +05.59 & -14.84 & -27.99 & nc & -01.17 \\
\hline $\begin{array}{l}+25 \% \\
+50 \%\end{array}$ & -00.41 & -08.88 & +09.93 & -25.81 & -45.54 & nc & -01.40 \\
\hline D. $500 \%$ & $\mathrm{nc}$ & nc & nc & nc & -50.01 & nc & nc \\
\hline R - $50 \%$ & $\mathrm{nc}$ & nc & $\mathrm{nc}$ & $\mathrm{nc}$ & -25.02 & nc & nc \\
\hline$-25 \%$ & $\mathrm{nc}$ & nc & nc & $\mathrm{nc}$ & +24.99 & $\mathrm{nc}$ & $\mathrm{nc}$ \\
\hline $\begin{array}{l}+25 \% \\
+50 \%\end{array}$ & $\mathrm{nc}$ & nc & nc & $\mathrm{nc}$ & +49.98 & nc & nc \\
\hline & +02.08 & -02.50 & +22.48 & -08.27 & -07.27 & nc & +00.34 \\
\hline$C_{s}-50 \%$ & +01.04 & -01.29 & +01.24 & -04.34 & -03.82 & nc & +00.18 \\
\hline$-25 \%$ & -01.04 & +01.29 & -01.24 & +06.38 & +03.68 & $\mathrm{nc}$ & -01.75 \\
\hline$+25 \%$ & -01.87 & +02.58 & -02.48 & +09.31 & +08.05 & nc & -03.42 \\
\hline$+50 \%$ & +02.08 & -27.14 & -31.67 & +41.04 & -64.56 & nc & -54.56 \\
\hline D -50\% & +01.04 & -15.75 & -11.18 & $\begin{array}{l}+10.82 \\
\end{array}$ & -37.52 & nc & -27.31 \\
\hline$-25 \%$ & -01.04 & +23.10 & +01.86 & -01.74 & +53.60 & $\mathrm{nc}$ & +27.37 \\
\hline$+25 \%$ & -02.08 & +60.74 & -06.83 & +05.20 & +137.58 & nc & +54.80 \\
\hline$+50 \%$ & & & & & & & \\
\hline
\end{tabular}

*Indicates optimal solution, nc indicates no change solution, IC - inventory cost, RC - rework cost, SC - setup cost.

\section{Sensitivity Analysis}

From the sensitivity analysis of the Examples 1 (see Tables 1 ); it is observed that the optimal production rate $P^{*}$, lotsize $Q^{*}$, total inventory cost $\left(I C^{*}\right)$, total rework cost
$\left(R C^{*}\right)$, setup cost $\left(S C^{*}\right)$ and total expected profit per unit time $\left(E \pi^{*}\right)$ are fairly sensitive with changes of the key parameters ( $\alpha, \eta, \mathrm{g}, C_{h}, \mathrm{R}, C_{s}$, D). The optimal production cost of unit item $\mathrm{C}\left(P^{*}\right)$ is fairly sensitive with changes in the parameters g, ๆand $r_{m}$. From the sensitivity analysis of the above example (see Tables 1 and Figs. 5-9), the following facts occur:

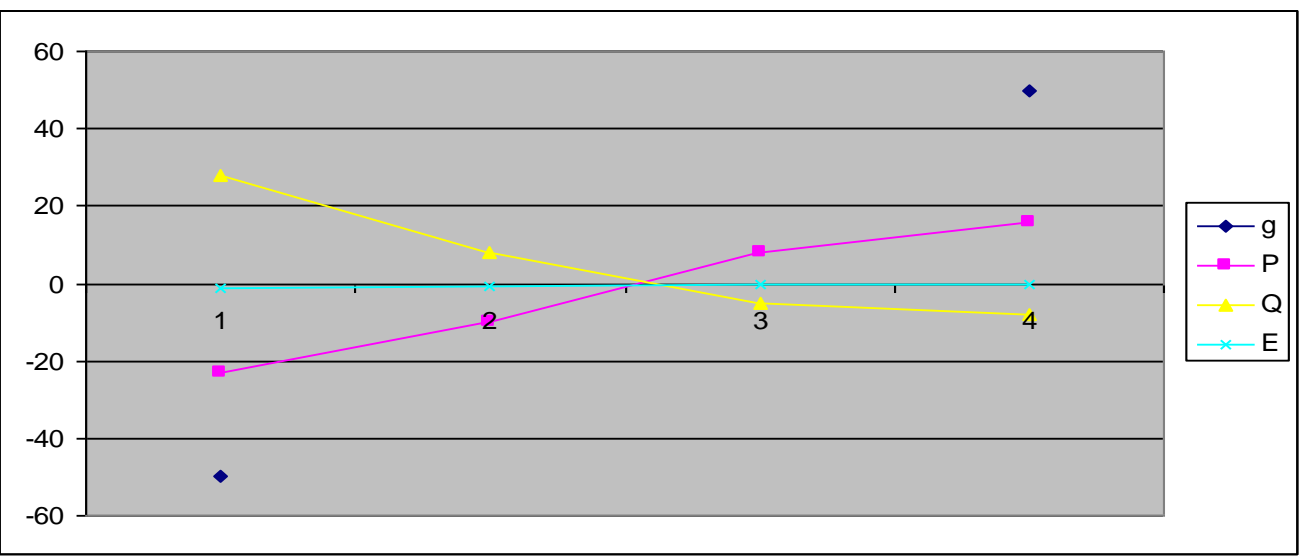

Figure 5: Change of optimal E $\pi, \mathrm{P}$ and Q (in \%), versus change of parameter " $\mathrm{g}$ ” (in \%) for Example 1.

\section{Volume 5 Issue 2, February 2016}


1. $P^{*}, Q^{*}, I C^{*}$ and $\mathrm{C}\left(P^{*}\right)$ increase with increases in labour/energy costs (g), whereas $R C^{*}, S C^{*}$ and $E \pi^{*}$ decrease with increases in g. It is quite natural that optimal production rate is higher for higher labour/energy costs, keeping in mind the cost minimization of production cost.
As production rate increases lot-size $Q^{*}$ automatically increases that results in higher inventory cost. Here, the change of production rate compared to the lot-size is higher. It provides lower production-run-time. Consequently, total rework cost and setup cost are higher in spite of higher production rate.

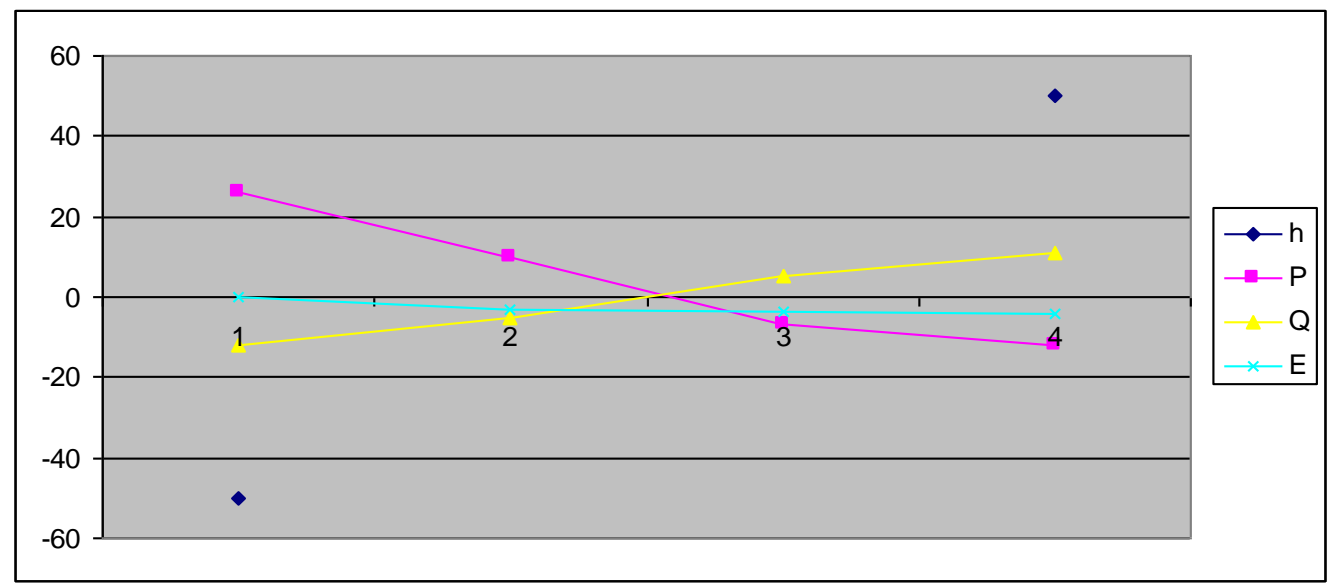

Figure 6: Change of optimal $E \pi, P$ and Q (in \%), versus change of parameter " $\eta$ ” (in \%) for Example 1.

2. With increases in tool/die costs, optimum production rate decreases obviously that results in lower lot size and inventory cost. It is also obvious that lower production rate and lot-size reduce total rework cost and setup cost. And, lower production rate causes higher unit production cost.

3. The production rate increases and lot-size decreases with increases in $\alpha$. Smaller lot-size causes lower inventory cost and higher setup cost as total demand is fixed. Higher production rate produces more defective items that results in higher rework cost.

4. $P^{*}, R C^{*}, S C^{*}$ increase and $Q^{*}, I C^{*}$ and $E \pi^{*}$ decrease with increases in $\mathrm{R}$. Although the production-run time decreases with increases in $\mathrm{R}$, the number of defective items is higher due to higher production rate that results in higher rework cost. Also, lower lot-size reduces the inventory cost and setup cost.

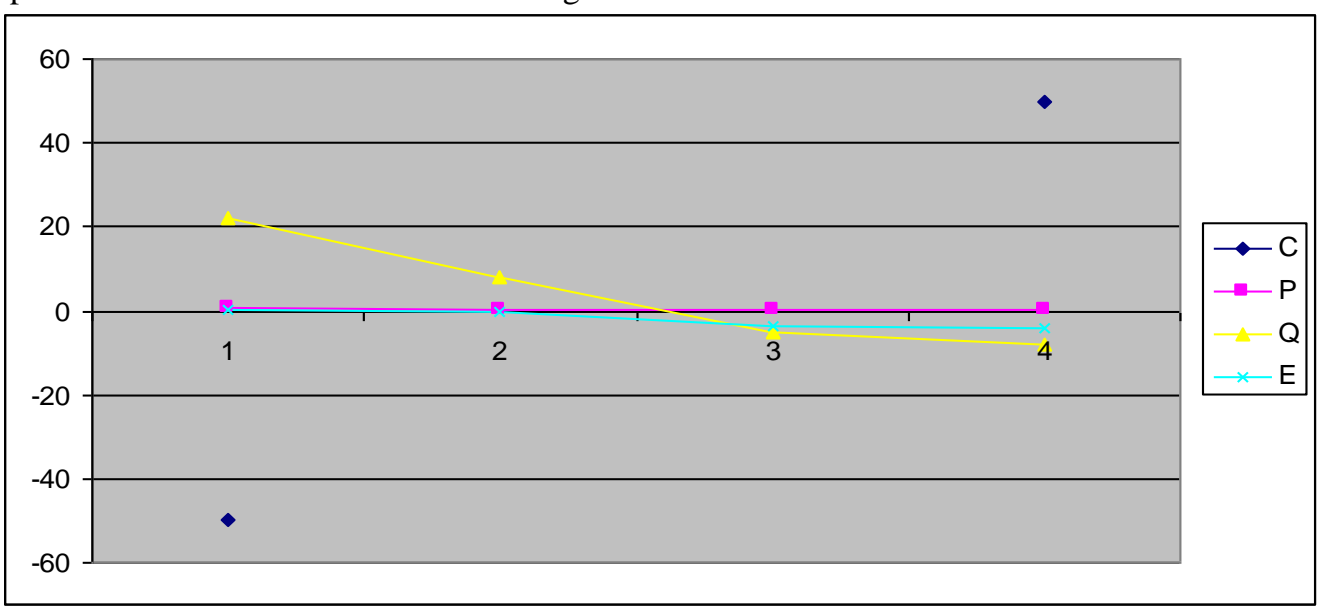

Figure 7: Change of optimal $\mathrm{E} \pi, \mathrm{P}$ and $\mathrm{Q}$ (in \%), versus change of parameter “ “ $C_{h}$ ” (in \%) for Example 1.

\section{Conclusion}

In this paper, we propose a generalized production lot size model with backordering. Our model extends the approach by Sana (2010) to consider permissible shortage backordering. We have maintained the originality of the model of Sana (2010) as he described that given the ongoing addition of new technology, the introduction of more robotics and automation, the increasing use of computeraided devices, etc., 'out-of-control' state is likely to be even higher with higher production rate. During 'out-of-control' state, the process starts to produce defective items. As the rate of production increases, the defective items are more produced. Generally speaking, the probability of defective items increases with increase of production-run-time because of machinery problems, impatience of labor staff and improper distribution of raw materials. Also, in long-run production process, the percentage of defective items increases with both the increase of production rate and production-run time. In this point of view, I have considered the rate of production of defective items (percentage of total production) is a nonlinear function of both production rate and production-run time. The probability distribution of shift time from 'in-control' state to an 'out-of-control' state 


\section{International Journal of Science and Research (IJSR) \\ ISSN (Online): 2319-7064}

Index Copernicus Value (2013): 6.14 | Impact Factor (2014): 5.611

follows an exponential distribution function with mean $1=f(P)$, where $f(P)$ is an increasing function of $P$. In the existing literature, everybody considers this percentage is a fixed constant throughout the production cycle. The defective items are reworked at a cost in a separate cell to restore its original quality. The reworking cost is measured by wasted materials, labor, equipment time and other resources. We have described the final results of Sana (2010) model as a particular case (Special case 2). We have used some things like shortage, unit production cost dependent selling price, and screening cost and found the optimal values of total cost and other costs in this situation. We have also determined the time period for different stage like shortage period, backlogging period, production run time, only demand period and total cycle time. I have obtained an optimal lot-size and production rate, solving by numerical techniques. And, the features of key parameters are studied in sensitivity analysis section.

\section{References}

[1] Hax,A.C. and Candea, D.,1984. Production and Inventory Management. Prentice-Hall, Englewood Cliffs, NJ.

[2] Schweitzer, P.J. and Seidmaan, A., 1991. Optimization processing rate for flexible manufacturing systems. Mgmt Sci. 37, 454-466.

[3] Drozda, T.J. and Wick, C. (Eds), 1987. Tool and Engneers Handbook, vol. 1. Society of Mathematical Engneers,Dearborn, MI

[4] Rosenblatt, M.J., Lee, H.L., 1986. Economic production cycles with imperfect production processes. IIE Transactions 17, 48-54.

[5] Lee, H.L., Rosenblatt, M.J., 1987. Simultaneous deterioration of production cycle and inspection schedules in a production system. Management Science 33, 1125-1136.

[6] Lee, H.L., Rosenblatt, M.J., 1989. A production and maintenance planning model with restoration cost dependent on detection delay. IIE Transactions 21 (4), 368-375.

[7] Cheng, T.C.E., 1991. An economic order quantity model with demand dependent unit production cost and imperfect production processes. IIE Transactions 23, 23-28.

[8] Khouja, M., Mehrez, A., 1994. An economic production lot size model with imperfect quality and variable production rate. Journal of the Operational Research Society 45, 1405-1417.

[9] Hariga, M., Ben-Daya, M., 1998. Note: the economic manufacturing lot-sizing problem with imperfect production process: Bounds and optimal solutions. Naval Research Logistics 45, 423-432.

[10] Kim, C.H., Hong, Y., 1999. An optimal production run length in deteriorating production processes. International Journal of Production Economics 58, 183192.

[11] Makis, V., 1998. Optimal lot sizing and inspection policy for EMQ model with imperfect inspections. Naval Research Logistics Quaterly 45, 165-186.

[12] Wang, C.H., 2004. The impact of a free-repair warranty policy on EMQ model for imperfect production systems. Computers \& Operations Research 31, 20212035.

[13] Yeh, R.H., Ho, W.T., Tseng, S.T., 2000. Optimal production run length for products sold with warranty. European Journal Operational Research 120, 575-582.

[14] Sheu, S.H., Chen, J.A., 2004. Optimal lot-sizing problem with imperfect maintenance and imperfect production. International Journal of Systems Science 35, 69-77.

[15] Lee, H.H., 2005a. Quality Management. Tsang-Hai, Inc., ROC.

[16] Lee, H.H., 2005b. Cost/benefit model for investments in inventory and preventive maintenance in imperfect production system. Computers \& Industrial Engineering 48, 55-68.

[17]Lee, H.H., 2005c.Cost model with rolled throughput yield for six sigma management. Journal of Quality 33, 231-237

[18] Chen, C.K., Lo, C.C., 2006. Optimal production run length for products sold with warranty in an imperfect production system with allowable shortages. Mathematical And Computer Modeling 44, 319-331.

[19]Lee, H.H., 2006. Investment equipment in imperfect production systems. International Journal of Advanced Manufacturing Technology 31, 278-282.

[20] Sana, S., Gogal, S.K., Chaudhuri, K.S., 2007a. An imperfect production process in a volume flexible inventory model. International Journal of Production Economics 105, 548-559.

[21] Sana, S., Gogal, S.K., Chaudhuri, K.S., 2007b. On a volume flexible inventory model for items with an imperfect production system. International Journal of Operational Research 2 (1), 64-80.

[22] Giri, B.C., Dohi, T., 2007. Inspection scheduling for imperfect production process under free repair warranty contract. European Journal of Operational Research 183, 238-252.

[23]Liao, G.L., 2007. Optimal production correction and maintenance policy for imperfect process. European Journal of Operational Research 182, 1140-1149.

[24]Lo, S.T., Wee, H.M., Huang, W.C., 2007. An integrated production inventory model with imperfect production processes and Weibull distribution deterioration under inflation. International Journal of Production Economics 106, 248-260.

[25] Panda, D., Kar, S., Maity, K., Maiti, M., 2008. A single period inventory model with imperfect production and stochastic demand under chance and imprecise constraints.European Journal of Operational Research 188, 121-139.

[26] Lee, H.H., 2008. The investment model in preventive maintenance in multi-level production systems. International Journal of Production Economics 112, 816-828.

[27] Schwaller, R.L., 1988. EOQ under inspection costs. Production and Inventory Management 29, 22-24.

[28]Zhang, X., Gerchak, Y., 1990. Joint lotsizing and inspection policy in an EOQ model with random yield. IIE Transactions 22, 41-47.

[29] Salameh, M.K., Jaber, M.Y., 2000. economic production quantity model for items with imperfect quality. International Journal of Production Economics 64, 59-64. 
[30] Hayek, P.A., Salameh, M.K., 2001. Production lot sizing with the reworking of imperfect quality items produced. Production Planning and Control 12, 584590.

[31] Goyal, S.K., Cardenas-Barron, L.E., 2002. Note on economic production quantity model for items with imperfect quality - a practical approach. International Journal of Production Economics 77, 85-87.

[32] Chiu, Y.P., 2003. Determining the optimal lot size for the finite production model with random defective rate, the rework process, and backlogging. Engineering Optimization 35, 427-437.

[33] Chan, W.M., Ibrahim, R.N., Lochert, P.B., 2003. A new EPQ model: Integrating lower pricing, rework and reject situations. Production Planning and Control 14, 588-595.

[34] Chang, H.C., 2004. An application of fuzzy sets theory to the EOQ model with imperfect quality items. Computers and Operations Research 31, 2079-2092.

[35] Papachristos, S., Konstantaras, I., 2006. Economic ordering quantity models for items with imperfect quality. International Journal of Production Economics 100, 148-154.

[36] Maddah, B., Jaber, M.Y., 2008. Economic order quantity for items with imperfect quality: Revisited. International Journal of Production Economics 112, 808-815.

[37] Sana, S.S., 2010, An economic production lot size model in an imperfect production system. European Journal of Operational Research 201, 158-170

[38] Chung, K.J.and Hou, K.L.2003, An optimal production run time with imperfect production process and allowable shortage. Computer and operation research 30, 483-490 